\title{
Efeitos do extrato da parede de levedura na digestibilidade, no escore fecal e na palatabilidade de dietas para gatos
}

[Effects of spray-dried yeast cell wall on digestibility, score of feces, and palatability of diets for cats]

\author{
A.A. Aquino ${ }^{1}$, F.M.O.B. $\operatorname{Saad}^{2}$, J.P.F. Santos $^{1}$, M.P. Alves ${ }^{1}$, R.A. Ferrazza ${ }^{3}$, M.C.M.G. Miranda \\ ${ }^{1}$ Aluno de pós-graduação - UFLA - Lavras, MG \\ ${ }^{2}$ Departamento de Zootecnia - UFLA - Lavras, MG \\ ${ }^{3}$ Aluno de graduação - UFLA - Lavras, MG \\ ${ }^{4}$ Zootecnista
}

\section{RESUMO}

Para avaliar o efeito do extrato seco da parede de levedura (EPL) sobre a digestibilidade, o escore fecal e a palatabilidade de dietas para gatos, foram realizados três ensaios experimentais. No primeiro, 20 animais adultos foram distribuídos ao acaso em quatro tratamentos: dieta comercial úmida (controle) e dieta-controle $+0,2$, ou dieta-controle $+0,4$ ou dieta-controle $+0,6 \%$ de EPL na matéria seca. No segundo, utilizaram-se alimento seco e as mesmas proporções com o mesmo delineamento do primeiro experimento. No ensaio 3, de palatabilidade, 20 gatos adultos receberam simultaneamente dieta comercial úmida sem e com a inclusão de $0,4 \%$ de EPL. No experimento 1 , não foram observadas diferenças quanto à digestibilidade da matéria seca, proteína bruta, extrato etéreo, matéria orgânica e energia bruta, assim como no escore fecal; no segundo, houve aumento linear $(\mathrm{P} \leq 0,46)$ no coeficiente de digestibilidade da matéria seca, e, no terceiro, observou-se efeito negativo da inclusão de $0,4 \%$ sobre a palatabilidade da dieta $(\mathrm{P} \leq 0,004)$. Conclui-se que a inclusão de EPL em dietas úmidas não influi na digestibilidade, mas pode comprometer a palatabilidade, e que em dietas secas há melhora da digestibilidade da matéria seca.

Palavras-chave: gato, mananoligossacarídeo, prebiótico, alimento comercial

\begin{abstract}
The effects of spray-dried yeast cell wall (YCW) were evaluated on digestibility, score of feces, and palatability of diets for cats were evaluated. Three trials were carried out. In the first, 20 adult cats were randomly allotted in four treatments: wet commercial diet (control) and control plus 0.2, 0.4, or 0.6\% of $Y C W$ in dry matter. In the second, a commercial dry diet was tested in an equal arrangement concerning concentration of YCW and number of animals of the first trial. In the third, 20 adult cats were fed at the same time a wet diet with or without $0.4 \% \mathrm{YCW}$. In the first trial, no differences among treatments for dry matter, crude protein, ether extract, organic matter, gross energy digestibility, and faecal score were observed. In second trial, positive linear effect on dry matter digestibility $(P=0.046)$ was observed. In the third, negative effect of $0.4 \%$ YCW inclusion $(P=0.004)$ on palatability of diet was observed. It was concluded that YCW inclusion in wet diet did not effectively alter the nutrients digestibilities but it decrease the palatability. However, the YCW inclusion in dry diets can be important to improve dry matter digestibility.
\end{abstract}

Keywords: cat, mannanoligosaccharide, prebiotic, commercial diet

\section{INTRODUÇÃO}

Com o desenvolvimento das técnicas de diagnóstico e de tratamento na medicina veterinária, a expectativa de vida dos animais de companhia tem aumentado consideravelmente. No entanto, o conceito de maior longevidade está atrelado ao de qualidade de vida. Por esse

Recebido em 21 de abril de 2009

Aceito em 3 de maio de 2010

E-mail: adrianaaquino@veterinaria.med.br 
motivo, é importante desenvolver estratégias que permitam a maximização das funções fisiológicas. A nutrição desempenha papel fundamental nesse processo, e oferecer uma alimentação adequada pode ser uma medida de saúde preventiva. Neste contexto, os ingredientes funcionais, como os prebióticos, assumem lugar de destaque. Os prebióticos podem ser definidos como ingredientes não digeríveis que beneficiam o hospedeiro, estimulando seletivamente o crescimento e a atividade de uma ou mais bactérias benéficas intestinais e melhorando a saúde do animal (Gibson e Roberfroid, 1995).

Prebióticos têm sido descritos e estudados e, dentre eles, destaca-se o extrato seco da parede celular de levedura (EPL). A parede celular de Saccharomyces cerevisae é composta por duas frações: uma mais interna, formada por beta 1,3 glucano e quitina, e outra, mais externa, constituída por manoproteínas que contêm cerca de 30-50\% de mananoligossacarídeo (MOS). Devido a essa constituição particular, o EPL tem mostrado capacidade de modular a microbiota intestinal e, dessa forma, levar a uma série de benefícios decorrentes da seleção bacteriana, como melhora na digestibilidade de nutrientes (Middelbos et al., 2007). Isso ocorre porque a ação dos microrganismos no trato digestório influenciaria a quantidade, a biodisponibilidade e a digestibilidade de alguns nutrientes da dieta. A fermentação de produtos lácteos por bactérias láticas, por exemplo, pode aumentar a concentração de determinados nutrientes, como vitaminas do complexo B. Do mesmo modo, a hidrólise enzimática bacteriana pode melhorar a digestibilidade de proteínas e de gordura e a liberação de aminoácidos livres (Saad, 2006).

No entanto, além da digestibilidade, em nutrição de felinos, a palatabilidade assume importância essencial. Isso ocorre devido à grande sensibilidade desses animais às variações na composição do alimento. Seus nervos faciais são extremamente sensíveis a aminoácidos e menos responsivos a mono e a dissacarídeos, e nenhum sistema fisiológico relacionado à percepção do açúcar foi identificado (Bradshaw et al., 1996). Alguns subprodutos de levedura, como o extrato, têm sido estudados (Lima, 2008), mas não há trabalhos na literatura consultada que avaliassem o efeito da inclusão de EPL sobre a palatabilidade das dietas.
Dessa forma, os objetivos desta pesquisa foram avaliar o efeito de teores crescentes de EPL, 0\%, $0,2 \%, 0,4 \%$ e $0,6 \%$, na matéria seca da dieta, para gatos adultos sobre a digestibilidade dos nutrientes e da energia em dietas comerciais úmida e seca, bem como o efeito da inclusão de $0,4 \%$ de EPL sobre a palatabilidade da dieta úmida.

\section{MATERIAL E MÉTODOS}

Foram realizados três ensaios experimentais. No primeiro, foram utilizados 20 gatos adultos, sem raça definida, machos e fêmeas, com média de peso de $3,71 \pm 0,84 \mathrm{~kg}$, escore corporal 3 (na escala de 1 a 5) e média de idade de três anos, alojados em sala de metabolismo e mantidos em gaiolas metabólicas. Os bebedouros eram individuais do tipo chupeta, e o alimento foi fornecido em potes plásticos. Os animais selecionados passaram por avaliação médicoveterinária antes e durante a realização do ensaio.

O delineamento experimental foi inteiramente ao acaso, com quatro tratamentos e cinco repetições. A duração total do ensaio foi de 30 dias, sendo 25 destinados à adaptação e os cinco últimos, à coleta de dados. Os tratamentos fornecidos a cada um dos grupos foram: controle, constituído por uma dieta comercial úmida padrão ou por uma dieta comercial úmida acrescida de 0,2 ou 0,4 , ou $0,6 \%$ de extrato seco da parede de levedura (EPL) na matéria seca. As quantidades de alimento oferecidas foram baseadas nas necessidades energéticas estimadas pela equação 100kcal x PV (Nutrient..., 2006), e a estimativa da energia do alimento foi estimada segundo o NRC (Nutrient..., 2006). O EPL foi misturado individualmente em cada um dos potes, e a água foi fornecida à vontade.

No segundo experimento, foram utilizados 20 gatos adultos, sem raça definida, machos $\mathrm{e}$ fêmeas, com três anos, média de $3,56 \mathrm{~kg} \pm 0,78 \mathrm{~kg}$ e escore de condição corporal 3 (escala de 1 a 5). Os animais foram distribuídos ao acaso em quatro tratamentos e cinco repetições. A duração total do ensaio foi de 25 dias, sendo 20 destinados à adaptação e os cinco últimos, à coleta de dados. Os tratamentos fornecidos a cada um dos grupos foram: controle, constituído por uma dieta comercial seca padrão ou por uma dieta comercial seca acrescida de 0,2 ou 0,4 ou $0,6 \%$ de EPL na matéria seca. As quantidades de 
alimento e a estimativa da energia também foram calculadas segundo o NRC (Nutrient..., 2006). O EPL foi misturado em cada um dos potes a partir da utilização de uma concentração padronizada de água (1,92 vez a quantidade de ração fornecida), e a água foi fornecida à vontade.

Nos dois experimentos, cerca de 500 gramas de alimento, correspondentes a cada um dos tratamentos, foram armazenados para posteriores análises de composição. $\mathrm{O}$ alimento foi fornecido uma vez ao dia, e a coleta total de fezes realizada no período da manhã. No momento da coleta, foi determinado o escore fecal segundo a escala utilizada por Swanson et al. (2002). Sobras de dietas e as fezes foram pesadas, armazenadas em sacos plásticos e congeladas a $-20^{\circ} \mathrm{C}$, diariamente. Posteriormente, amostras das dietas e das fezes, após ser composta uma amostra por animal, foram submetidas à pré-secagem em estufa, a $65^{\circ} \mathrm{C}$, durante 72 horas, pesadas, moídas em moinho analítico provido de peneira de $1 \mathrm{~mm}$ e armazenadas para análises de composição segundo a AOAC (Official..., 1995). As sobras foram analisadas quanto à matéria seca. $\mathrm{O}$ coeficiente de digestibilidade foi calculado pela fórmula: CDnutriente $=\left[\begin{array}{ll}\mathrm{g} & \mathrm{de} \\ \text { alimento }\end{array}\right.$ consumido $\mathrm{x} \%$ do nutriente no alimento)-( $\mathrm{g}$ de fezes $\mathrm{x} \%$ do nutriente excretado $)] /(\mathrm{g}$ de alimento consumido $\mathrm{x} \%$ do nutriente no alimento) $\mathrm{x} 100$. A composição química bem como os ingredientes de ambas as dietas são apresentados na Tab. 1.

Tabela 1. Composição química analisada (\% da matéria natural) e composição básica dos alimentos (*) úmido e seco $(* *)$

\begin{tabular}{lcc}
\hline Nível nutricional & Dieta úmida & Dieta seca \\
\hline Umidade & 78,00 & 7,17 \\
Proteína bruta & 9,85 & 32,34 \\
Extrato etéreo & 5,09 & \\
Fibra bruta & 0,17 & 6,62 \\
Matéria mineral $^{\text {Extrativo não nitrogenado }}{ }^{1}$ & 2,50 &
\end{tabular}

* Água, carne de frango, miúdos de bovinos, miúdos de aves, miúdos de suínos, cloreto de sódio (sal comum), carragena, taurina, premix vitaminico mineral. ** Arroz quebrado, farinha de vísceras, farelo de glúten de milho-60, milho integral moído, farelo de soja, farinha de peixe, gordura de frango, carne de ovelha em pó, semente de linhaça, levedura seca, hidrolisado de frango e/ou subprodutos, fosfato bicálcico, cloreto de sódio (sal comum), cloreto de potássio, colina e premix vitamínico mineral. ${ }^{1}$ Extrativo não nitrogenado $=100-(\mathrm{PB}+\mathrm{EE}+\mathrm{FB}+\mathrm{MM})$

O terceiro experimento consistiu em um ensaio de palatabilidade, com duração de 10 dias, quatro de adaptação e seis de coleta. Foram utilizados 20 gatos adultos, sem raça definida, com média de peso de $3,65 \pm 0,79 \mathrm{~kg}$, em um total de 120 observações. Os animais, de três anos de idade e escore corporal 3 (escala de 1 a 5), foram alojados em gaiolas metabólicas.

$\mathrm{Na}$ fase de adaptação, os gatos receberam um alimento comercial úmido padrão, diferente do que foi utilizado na coleta, com a finalidade de evitar a ocorrência de neofobia. Nessa etapa, foram calculadas as necessidades energéticas dos animais com o acréscimo de $30 \%$ para fornecimento do alimento no primeiro dia. Ajustes foram realizados dia a dia para cada animal, de acordo com as sobras obtidas, de forma a garantir, pelo menos, $15 \%$ de sobras. $\mathrm{O}$ alimento era dividido em duas vasilhas.
$\mathrm{Na}$ fase de coleta, os animais receberam duas vasilhas, cada uma contendo a quantidade de alimento ajustada no período de adaptação. Em uma delas, havia apenas alimento comercial úmido, e na outra, o mesmo alimento com $0,4 \%$ de EPL. $\mathrm{O}$ aditivo foi incorporado à dieta com $\mathrm{o}$ auxílio de uma colher, e o pote que continha a dieta-controle (sem EPL) foi misturado para evitar efeito de consistência sobre o consumo. Os gatos foram alimentados, todos os dias, às oito horas da manhã, e as vasilhas ficaram disponíveis durante 24 horas. Para evitar efeitos de lateralidade, os potes foram alternados no posicionamento, ora colocados à direita do animal, ora à esquerda. Os níveis de garantia e a composição dos alimentos da fase de adaptação e da fase de coleta são apresentados na Tab. 2. 
Efeitos do extrato da parede...

Tabela 2. Nível de garantia (\% da matéria natural) e composição básica da dieta úmida da fase de adaptação $(*)$ e de coleta $(* *)$

\begin{tabular}{lcc}
\hline Nível nutricional & Alimento (fase de adaptação) & Alimento (fase de coleta) \\
\hline Umidade (máx) & 80 & 80 \\
Proteína bruta (mín) & 8 & 8 \\
Extrato etéreo (mín) & 3 & 3 \\
Fibra bruta (máx) & 1,5 & 1,5 \\
Matéria mineral (máx) & 2,5 & 2,5 \\
Cálcio (máx) & 0,4 & 0,4 \\
Fósforo (mín) & 0,2 & 0,2 \\
Taurina (mín) & 0,05 & 0,05 \\
\hline * Água, atum, sardinha, carne de frango, miúdos de bovinos, miúdos de aves, miúdos de suínos, gordura animal \\
estabilizada, óleo de peixe refinado, carragena, premix vitamínico e mineral, tripolifosfato de sódio, taurina ** Água, \\
carne de frango, miúdos de bovinos, miúdos de aves, miúdos de suínos, cloreto de sódio (sal comum), carragena, \\
taurina, premix vitaminico mineral.
\end{tabular}

Os resultados dos dois primeiros ensaios foram analisados no programa SAS/2004. As variáveis quantitativas foram submetidas à regressão polinomial simples por meio do PROC GLM, e o escore fecal, à estatística não paramétrica (teste Kruskal Wallis) pelo PROC NPAR1WAY. Para o teste de palatabilidade, utilizou-se o PROC GLM do SAS, considerando-se como fontes de variação o peso, o tratamento, o dia e a interação versus alimento/dia. Foi considerado o nível de $5 \%$ para todos os parâmetros avaliados.

\section{RESULTADOS E DISCUSSÃO}

No primeiro ensaio, a média geral de consumo, $50,41 \mathrm{~g} / \mathrm{dia}$, foi cerca de $20 \%$ abaixo da quantidade fornecida, $63 \mathrm{~g}$ (Tab. 3). No entanto, o menor consumo não afetou a estabilidade de peso dos animais, e a média, $3,71 \mathrm{~kg}$, permaneceu inalterada. $\mathrm{O}$ consumo médio de proteína e lipídeos atendeu às necessidades mínimas preconizadas pela AAFCO (Official ..., 2007). Não houve efeito significativo de tratamentos, o que evidencia que a inclusão de até $0,6 \%$ de EPL não afeta a aceitabilidade de dietas úmidas. Estes resultados assemelham-se aos observados, em cães, por Swanson et al. (2002), que não verificaram efeitos da inclusão de $0,3 \%$ de mananoligossacarídeos (MOS) sobre a aceitabilidade.

Em relação ao coeficiente de digestibilidade de energia e de nutrientes e à concentração de energia digestível na matéria seca e na matéria natural, não foram observadas diferenças significativas entre tratamentos (Tab. 4).

Tabela 3. Consumo de nutrientes (g/dia) e de energia (kcal/dia) com dieta úmida por gatos, segundo os tratamentos

\begin{tabular}{|c|c|c|c|c|c|}
\hline \multirow{2}{*}{ Variável } & \multicolumn{4}{|c|}{ Tratamento (\% EPL) } & \multirow{2}{*}{$\begin{array}{l}\mathrm{CV} \\
(\%)\end{array}$} \\
\hline & 0 & 0,2 & 0,4 & 0,6 & \\
\hline CMS & 52,05 & 53,86 & 54,33 & 42,18 & 23,24 \\
\hline CPB & 23,31 & 23,16 & 24,32 & 18,60 & 23,34 \\
\hline CEE & 12,04 & 12,43 & 11,94 & 9,62 & 23,14 \\
\hline CMM & 6,09 & 5,90 & 6,23 & 4,56 & 24,38 \\
\hline CMO & 45,96 & 47,95 & 48,10 & 37,62 & 23,12 \\
\hline CEB & 296,70 & 305,91 & 312,43 & 234,94 & 23,75 \\
\hline
\end{tabular}

EPL: extrato seco da parede celular de levedura; CV: coeficiente de variação; C: consumo; MS: matéria seca; PB: proteína bruta; EE: extrato etéreo; MM: matéria mineral; MO: matéria orgânica; EB: energia bruta. $\mathrm{P}>0,05$ pela regressão polinomial simples. 
Tabela 4. Coeficientes de digestibilidade de nutrientes e de energia (\%) e energia digestível na matéria seca e na matéria natural (kcal/kg) com dieta úmida, observadas em gatos, segundo os tratamentos

\begin{tabular}{|c|c|c|c|c|c|}
\hline \multirow{2}{*}{ Variável } & \multicolumn{4}{|c|}{ Tratamentos (\% EPL) } & \multirow{2}{*}{$\begin{array}{l}\mathrm{CV} \\
(\%)\end{array}$} \\
\hline & 0 & 0,2 & 0,4 & 0,6 & \\
\hline CDMS & 74,09 & 77,60 & 79,83 & 78,26 & 5,15 \\
\hline CDPB & 75,15 & 76,96 & 80,72 & 78,08 & 2,32 \\
\hline CDEE & 80,32 & 82,04 & 83,47 & 82,29 & 7,52 \\
\hline CDMM & 39,53 & 45,05 & 52,66 & 50,44 & 12,91 \\
\hline CDMO & 79,03 & 80,91 & 82,34 & 79,31 & 3,72 \\
\hline CDEB & 78,96 & 80,97 & 83,09 & 82,21 & 3,93 \\
\hline EDMS & 4502,00 & 4596,00 & 4775,00 & 4580,00 & 4,03 \\
\hline EDMN & 990,20 & 1012,00 & 1051,25 & 1007,60 & 4,04 \\
\hline
\end{tabular}

EPL: extrato seco da parede celular de levedura; CV: coeficiente de variação; CD: coeficiente de digestibilidade; MS: matéria seca; PB: proteína bruta; EE: extrato etéreo; MM: matéria mineral; MO: matéria orgânica; EB: energia bruta; ED: energia digestível; MS: matéria seca; MN: matéria natural.

$\mathrm{P}>0,05$ pela regressão polinomial simples.

Os coeficientes de digestibilidade dos nutrientes e da energia bruta situaram-se dentro dos parâmetros para alimentos comerciais destinados a felinos segundo Numajiri (2006), que encontrou valores de digestibilidade da matéria seca variando de $64,8 \%$ a $81,5 \%$. No entanto, ficaram abaixo do encontrado por Lima (2008), que observou digestibilidade de $80,8 \%$, para um alimento úmido para gatos.

Em relação à ausência de efeito pela inclusão do EPL, os resultados foram semelhantes ao de Swanson et al. (2002), que trabalharam com cães, mas diferentes dos obtidos por Middelbos et al. (2007), que encontraram efeito cúbico na digestibilidade da matéria seca, tendo o maior valor sido alcançado com a utilização de 0,25\% de EPL, e o pior, com $0,65 \%$. Zentek et al. (2002) também verificaram redução significativa da digestibilidade das dietas suplementadas com cerca de 5\% de MOS.

Quanto ao coeficiente de digestibilidade da proteína bruta, a ausência de efeito de tratamento difere do observado nos trabalhos já mencionados. Em todos eles, houve diminuição significativa no aproveitamento da proteína, sendo esta a principal causa citada pelos autores para a diminuição dos coeficientes de digestibilidade da matéria seca e da matéria orgânica nesses estudos. A razão para tal efeito seria a aglutinação dos MOS à proteína. No presente estudo, esse efeito não ocorreu, o que contribuiu para a manutenção da digestibilidade da matéria seca e da matéria orgânica. O coeficiente de digestibilidade do extrato etéreo assim como o da matéria mineral também não foram modificados pela inclusão de EPL na dieta. O resultado para o extrato etéreo difere do obtido por Middelbos et al. (2007), que encontraram melhor digestibilidade com $0,45 \%$ de EPL.
Para a energia, nenhuma alteração foi verificada, o que poderia ser decorrente da manutenção na digestibilidade de proteínas e extrato etéreo. Os valores de energia digestível diferem do previamente calculado pela equação do NRC (Nutrient..., 2006), para este alimento. Os resultados situaram-se dentro do esperado para alimentos destinados a felinos, conforme Numajiri (2006), que encontrou variações de 3.188,34 a $4.531,34 \mathrm{kcal} / \mathrm{kg}$ para a energia digestível na matéria natural, e de $3.471,16$ a $4.807,47 \mathrm{kcal} / \mathrm{kg}$ para a energia na matéria seca. Em relação aos alimentos úmidos, Lima (2008) encontrou valores de energia digestível na matéria seca de $4.795,25 \mathrm{kcal} / \mathrm{kg}$. Os resultados para o escore fecal estão na Tab. 5 .

Não houve diferença significativa $(\mathrm{P}=0,179)$ para o escore fecal, e os resultados são um reflexo do que foi observado com a digestibilidade dos nutrientes. Isso significa que a adição de EPL não promoveu melhora na qualidade das fezes. De qualquer forma, mais de $40 \%$ delas, em todos os tratamentos, apresentaram escore 3, compatível com os resultados obtidos com a utilização de alimentos úmidos. Concentrações muito elevadas de EPL poderiam estar associadas à piora no escore fecal pela osmose, embora esses efeitos sejam, em geral, muito menores do que os associados ao excesso de outras substâncias prebióticas. Zentek et al. (2002), ao utilizarem 5\% de MOS na dieta de cães, não encontraram diferenças no escore fecal em relação à dieta basal, mas relataram diminuição na matéria seca das fezes, em porcentagem, isto é, $31,6 \%$ para animais suplementados versus $36,8 \%$ para os alimentados com a dieta basal reestabelecida após a suplementação. 
Efeitos do extrato da parede...

Tabela 5. Distribuição percentual do escore fecal de amostras obtidas de gatos alimentados com dieta úmida, segundo os tratamentos

\begin{tabular}{ccccc}
\hline \multirow{2}{*}{ Escore } & \multicolumn{5}{c}{ Tratamento (\% EPL) } \\
\cline { 2 - 5 } & Controle & 0,2 & 0,4 & 0,6 \\
\hline 1 & 0 & 0 & 0 & 0 \\
2 & 11 & 4 & 15 & 14 \\
3 & 59 & 43 & 55 & 45 \\
4 & 30 & 46 & 25 & 36 \\
5 & 0 & 7 & 5 & 5 \\
Total & 100 & 100 & 100 & 100 \\
\hline
\end{tabular}

*Não significativo pelo teste Kruskal-Wallis. EPL: extrato seco da parede celular de leveduras

No experimento 2, a média geral para o consumo de matéria seca esteve, em média, $25 \%$ abaixo das exigências calculadas pela equação $100 \mathrm{x}$ $\mathrm{PV}^{0,67}$. Dessa forma, o consumo de proteína bruta de matéria orgânica e o de energia bruta também sofreram alterações, mas a ingestão proteica atendeu às necessidades preconizadas pela AAFCO (Official ..., 2007). Houve efeito quadrático da inclusão de EPL sobre o consumo de matéria seca (Tab. 6). No entanto, o menor consumo não alterou a estabilidade de peso dos animais, e a média de $3,56 \mathrm{~kg}$ permaneceu inalterada.

Nenhum efeito significativo para os coeficientes de digestibilidade de nutrientes e energia e para a energia digestível na matéria seca e natural foi observado pela adição de EPL à dieta (Tab. 7).

Tabela 6. Consumo de nutrientes (g/dia) e de energia (kcal/dia) com dieta seca por gatos, segundo os tratamentos

\begin{tabular}{lcccccc}
\multirow{2}{*}{ Variável } & \multicolumn{9}{c}{ Tratamento (\% EPL) } & & CV & Valor de P \\
\cline { 2 - 4 } & 0 & 0,2 & 0,4 & 0,6 & $(\%)$ & Q \\
\hline CMS & 49,23 & 45,75 & 34,87 & 50,63 & 24,43 & $0,0414^{1}$ \\
CPB & 17,15 & 16,46 & 12,31 & 18,66 & 24,85 & $0,0319^{2}$ \\
CMM & 3,48 & 3,40 & 2,59 & 3,75 & 24,02 & NS \\
CMO & 45,75 & 42,35 & 32,27 & 46,87 & 24,48 & $0,0422^{3}$ \\
CEB & 250,22 & 228,16 & 176,02 & 256,30 & 24,54 & $0,0319^{4}$ \\
\hline
\end{tabular}

EPL: extrato seco da parede celular de levedura; CV: coeficiente de variação; Q: efeito quadrático; NS: não significativo; C: consumo; MS: matéria seca; PB: proteína bruta; MM: matéria mineral; MO: matéria orgânica; EB: energia bruta. ${ }^{1} \mathrm{CMS}=50,93-75,53$ trat $+120,31$ trat $^{2} ; \mathrm{R}^{2}=0,6209 ;{ }^{2} \mathrm{CPB}=17,84-26,24$ trat $+44,06$ trat $^{2} ; \mathrm{R}^{2}=$ 0,$5600 ;{ }^{3} \mathrm{CMO}=47,32-70,84$ trat $+112,45$ trat $^{2} ; \mathrm{R}^{2}=0,6289 ;{ }^{4} \mathrm{CEB}=258,34-400,70$ trat $+639,58$ trat $^{2} ; \mathrm{R}^{2}=$ 0,6696 .

Tabela 7. Coeficientes de digestibilidade de nutrientes e de energia (\%) e energia digestível na matéria natural e na matéria seca $(\mathrm{kcal} / \mathrm{kg})$ com dieta seca, observados em gatos, segundo os tratamentos

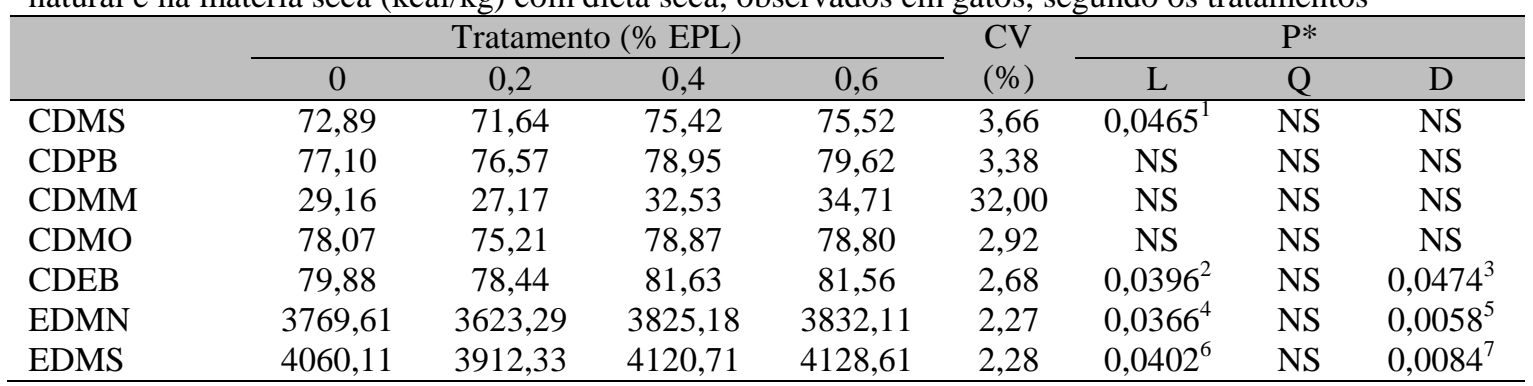

EPL: extrato seco de parede celular de levedura; C.V: coeficiente de variação; L: efeito linear; Q: efeito quadrático; D: efeito desvio; NS: não significativo; CD: coeficiente de digestibilidade; MS: matéria seca; PB: proteína bruta; EE: extrato etéreo; MM: matéria mineral; MO: matéria orgânica; EB: energia bruta; EDMN: energia digestível na matéria natural; EDMS: energia digestível na matéria seca; ${ }^{1} \mathrm{R}^{2}: 0,6161, \mathrm{y}=72,1178+5,8340 \mathrm{x} ;{ }^{2} \mathrm{R}^{2}: 0,2844,{ }^{3} \mathrm{R}^{2}: 0,5537$; ${ }^{4} \mathrm{R}^{2}: 0,5474 ;{ }^{5} \mathrm{R}^{2}: 0,5229 ;{ }^{6} \mathrm{R}^{2}: 0,5418 ;{ }^{7} \mathrm{R}^{2}: 0,5493$. 
Estes resultados diferem dos encontrados por Swanson et al. (2002) e Zentek et al. (2002) para cães em que uma diminuição da utilização da proteína bruta foi verificada. No entanto, foi possível observar efeito linear significativo sobre o consumo da matéria seca, o que poderia ser decorrente da melhora na digestibilidade de outros nutrientes. No trabalho realizado por Middelbos et al. (2007), com a utilização de EPL para cães, houve efeito cúbico sobre a digestibilidade de nutrientes. Zentek et al. (2002) observaram maior digestibilidade da fibra bruta em cães suplementados com EPL. Além disso, a suplementação com EPL pode aumentar a viscosidade da dieta, diminuindo a taxa de passagem e permitindo aumento do tempo de exposição da digesta às enzimas digestivas (Middelbos et al., 2007). No entanto, esperar-seia que maior viscosidade fosse obtida com os maiores níveis de suplementação, o que não ocorreu no experimento de Middelbos et al. (2007) e parece não ter ocorrido neste experimento.

Quanto ao coeficiente de digestibilidade da energia bruta, houve efeito linear, com aumento significativo nos tratamentos com $0,4 \%$ e $0,6 \%$ em relação ao tratamento controle, o que acompanharia as alterações observadas na digestibilidade da matéria seca. No entanto, é necessário considerar que uma leve queda no tratamento de $0,6 \%$ gerou simultaneamente um efeito desvio e que o $\mathrm{R}^{2}$ das equações foi muito baixo, o que inviabiliza o modelo de regressão para explicar tal alteração. $\mathrm{O}$ maior valor de digestibilidade de energia $(81,6 \%)$ obtido com $0,40 \%$ de EPL na dieta foi semelhante ao encontrado por Middelbos et al. (2007), com cães, em cujo trabalho $0,45 \%$ possibilitou a obtenção de $89,7 \%$ de digestibilidade. Os resultados também estão de acordo com menores valores de digestibilidade para todos os nutrientes encontrados no trabalho do autor mencionado, quando a suplementação de $0,25 \%$ foi realizada, já que os coeficientes mais baixos neste estudo foram encontrados no tratamento 2 .

A média geral de energia digestível, $3.763 \mathrm{kcal} / \mathrm{kg}$, situou-se dentro do previamente calculado pela equação do NRC (Nutrient..., 2006), $3.600 \mathrm{kcal} / \mathrm{kg}$. Conforme ocorrido anteriormente com o coeficiente de digestibilidade, os valores de energia digestível na matéria seca e na matéria natural apresentaram, simultaneamente, efeito linear e cúbico, mas com valores baixos de $\mathrm{R}^{2}$, o que indica que o modelo não pode explicar bem as alterações sofridas pelos dados.

As médias para o escore fecal são apresentadas na Tab. 8.

Tabela 8. Distribuição percentual do escore fecal de amostras obtidas de gatos alimentados com dieta seca

\begin{tabular}{ccccc}
\hline \multirow{2}{*}{ Escore } & \multicolumn{4}{c}{ Tratamento (\%EPL) } \\
\cline { 2 - 5 } & Controle & 0,2 & 0,4 & 0,6 \\
\hline 1 & 0 & 0 & 0 & 0 \\
2 & 5 & 11 & 17 & 10 \\
3 & 60 & 47 & 61 & 55 \\
4 & 10 & 37 & 22 & 30 \\
5 & 25 & 5 & 0 & 5 \\
Total & 100 & 100 & 100 & 100 \\
\hline
\end{tabular}

*Não significativo pelo teste Kruskal-Wallis. EPL: extrato seco da parede celular de leveduras

Não houve diferença significativa $(P=0,362)$ na qualidade das fezes com a inclusão de EPL. Cerca de $55 \%$ das fezes foram classificadas como escore 3, que são definidas como macias e bem formadas e que estão dentro dos parâmetros esperados. Middelbos et al. (2007), ao avaliarem a influência de EPL em dietas para cães, não encontraram diferenças significativas da inclusão do aditivo sobre a qualidade das fezes.
No experimento 3, o consumo esteve dentro da necessidade energética diária calculada pela equação $100 \times$ PV $^{0,67}$ do NRC (Nutrient..., 2006). Houve efeito significativo e negativo da inclusão de $0,4 \%$ de EPL sobre a palatabilidade da dieta (Tab. 9). 
Efeitos do extrato da parede...

Tabela 9. Consumo (g) e consumo na matéria seca (g) de dieta úmida com ou sem adição de extrato seco da parede de levedura (EPL)

\begin{tabular}{lcc}
\hline Variável & Controle & EPL 0,4\% \\
\hline Consumo & $143,08 \mathrm{a}$ & $112,18 \mathrm{~b}$ \\
Consumo de matéria seca & $34,89 \mathrm{a}$ & $28,89 \mathrm{~b}$ \\
\hline
\end{tabular}

Valores seguidos por letras distintas na linha diferem entre si $(\mathrm{P}<0,05)$.

Há algum tempo tem sido relatada uma ambiguidade na percepção do sabor da Dmanose nos dois principais anômeros dessa substância. Enquanto a alfa-D-manose é fortemente adocicada (tipo sucrose), a beta-Dmanose apresenta gosto amargo (tipo quinina) (Steinhardt et al., 1962). A única diferença entre essas duas formas de manose é a troca no posicionamento do $\mathrm{H}$ e da $\mathrm{OH}$ no carbono 1 do anel de piranose. No entanto, essa diferença é suficiente para atuar em receptores distintos, provocando sensações diferentes ao paladar. Se uma mistura estiver em equilíbrio entre essas duas estruturas, é possível que seja encontrado um efeito ambíguo (Stewart et al., 1971).

Sabe-se que os felídeos não são capazes de detectar os sabores adocicados provenientes dos carboidratos, provavelmente devido a uma deficiência da proteína T1R2, pela ausência da expressão de um pseudogene relacionado $(\mathrm{Li}$ et al., 2005). Além disso, parecem possuir um receptor análogo ao amargo de seres humanos, respondendo de forma adversa a substâncias como quinina, tanino e alcaloides. Assim, a presença de sabor levemente adocicado e/ou amargo, gerado pela inclusão de $0,4 \%$, pode ter sido a responsável pela resposta negativa do EPL sobre a palatabilidade.

O EPL poderia ter efeito semelhante ao de edulcorantes artificiais no estímulo aos receptores. A sacarina, por exemplo, foi rejeitada por gatos, na concentração de $0,0001 \mathrm{M}$ (Bartoshuk et al., 1975).

Não foram encontrados estudos que avaliassem os efeitos de EPL sobre o consumo de alimentos em felinos domésticos (Nutrient..., 2006). Testes de palatabilidade com proporções maiores ou menores do que as utilizadas neste estudo não foram realizados; por esse motivo, não se pode fazer inferência além do que foi estudado.

\section{CONCLUSÕES}

Os níveis utilizados permitem constatar a efetividade do uso de extrato seco da parede de levedura em dietas secas para gatos sobre a digestibilidade da matéria seca. A inclusão de $0,4 \%$ em dieta comercial úmida parece comprometer a palatabilidade.

\section{REFERÊNCIAS BIBLIOGRÁFICAS}

BARTOSHUK, L.M.; JACOBS, H.L.; NICHOLS, T.L. et al. Taste rejection of nonnutritive sweeteners in cats. J. Comp. Physiol. Psychol., v.89, p.971-975, 1975.

BRADSHAW, J.W.; GOODWIN, D.; LEGRAND-DEFRETIN, V. et al. Food selection by the domestic cat, an obligate carnivore. Comp. Biochem. Physiol., v.114A, p.205-209, 1996.

GIBSON, G.R.; ROBERFROID, M.B. Dietary modulation of the human colonic microbiota: introducing the concept of prebiotics. J. Nutr., v.125, p.1401-1412, 1995.

LI, X.; LI, W.; WANG, H. et al. Pseudogenization of a sweet-receptor gene accounts for cats' indifference toward sugar. Plos Genet., v.1, p.27-35, 2005.

LIMA, L.M.S. Extrato de levedura (Saccharomyces cerevisae) em dietas para gatos adultos. 2008. 87f. Dissertação (Mestrado) Universidade Federal de Lavras, Lavras, MG.

MIDDELBOS, I.S.; GODOY, M.R.; FASTINGER, N.D. et al. A dose-response evaluation of spray-dried yeast cell wall supplementation of diets fed to adult dogs: effects on nutrient digestibility, immune indices, and fecal microbial populations. J. Anim. Sci., v.85, p.3022-3032, 2007. 
NUMAJIRI, L.N. Valores nutricionais de alimentos completos e equações de predição de energia metabolizável para gatos adultos. 2006. 85f. Dissertação (Mestrado) - Universidade Federal de Lavras, Lavras, MG.

NUTRIENT requirements of dogs and cats. Washington, DC: National Academy of Science, 2006. 398p.

OFFICIAL methods of analysis. 16.ed. Arlington: Association of Official Analytical Chemists (AOAC), 1995. 1018p.

OFFICIAL publication Atlanta: Association of American Feed Control Officials. (AAFCO), 2007. $512 \mathrm{p}$.

SAAD, S.M.I. Probióticos e prebióticos: o estado da arte. Rev. Bras. Cienc. Farm., v.42, p.1-16, 2006.
SWANSON, K.S.; GRIESHOP, C.M.; FLICKINGER, E.A. et al. Supplemental frutooligossacharides and mannanoligossaccharides influence immune function,ileal and total tract nutrients digestibilities, microbial populations and concentrations of protein catabolites in the large bowel of dogs. J. Nutr., v.132, p.980-989, 2002.

STEINHARDT JR., R.G.; CALVIN, A.D.; DODD, E.A. Taste-structure correlation with alpha-Dmannose and beta-D-mannose. Science, v.135, p.367-368, 1962.

STEWART, R.A.; CARRICO, C.K.; WEBSTER, R.L. et al. Physicochemical stereospecificity in taste perception of alpha-D-Mannose and beta-DMannose. Nature, v.234, p.220, 1971. (Abstract).

ZENTEK, J.; MARQUART, B.; PIETRZAK, T. Intestinal effects of mannanoligosaccharides, transgalactooligosaccharides, lactose and lactulose in dogs. J. Nutr., v.134, p.1682S-1684S, 2002. 